\title{
Plazma Transferli Ark (PTA) Yöntemi ile Üretilen WC Kompozit Kaplamalarda Enerji Girdisinin Mikroyapısal ve Tribolojik Özelliklere Etkisi
}

\author{
Koray Kılıçay ${ }^{1 *}$ \\ Geliş / Received: 13/03/2020 \\ Revize / Revised: 13/05/2020 \\ Kabul / Accepted: 24/05/2020
}

$\overline{\mathbf{O Z Z}}$

Bu çalışmada, plazma transferli ark (PTA) yöntemi ile 3 farklı enerji girdisi kullanılarak 1.2842 soğuk iş takım çeliği üzerinde tungsten karbür (WC) tozu ile yüzey modifikasyon işlemi uygulanmıştır. Enerji girdileri işlem sırasında farklı akım değerleri ve ilerleme hızları kullanılarak gerçekleştirilmiş̧ir. Numunelerin mikroyapı özellikleri optik mikroskop, SEM, EDS ve XRD analizleri ile belirlenmiştir. Sürtünme ve aşınma özellikleri pimdisk aşınma test yöntemi kullanılarak ASTM-G99 standartlarına göre belirlenmiştir. Aşıınan yüzeyler SEM ve EDS analizleri ile incelenerek aşınma mekanizmaları tespit edilmiştir. Yüzeyi alaşımlandırılmış numunelerin interdendritik bölgelerinde $\mathrm{WC}, \mathrm{Fe}_{3} \mathrm{~W}_{3} \mathrm{C}$ ve $\mathrm{Fe}_{7} \mathrm{C}_{3}$ gibi sert karbür yapıları oluşmuştur. Enerji girdilerinin etkisiyle interdendritik bölgelerin büyüklüğü değişmiş̧ir. Düşük enerji girdisi WC tozunun tam olarak ayrışmasını sağlamadığı için interdendritik bölgelerde daha az W içerikli karbür oluşturmuştur. Deneysel çalışmalar sonucunda optimum enerji girdisi olarak $0.9 \mathrm{~kJ} / \mathrm{mm}$ belirlenmiştir. WC kaplamalarda oluşan sert karbür fazlarının etkiyle sertlik yaklaşık 5 kat artmış ve aşınma oranı yaklaşık 7 kata kadar azalmıştır. WC kaplamaların ana aşınma mekanizması abrasif ve oksidatif aşınma olmuştur.

Anahtar Kelimeler-PTA yüzey modifikasyonu, Isı girdisi, Tungsten karbür, Sürtünme ve aşınma.

1*Sorumlu yazar iletişim: kkilicay@ogu.edu.tr (https://orcid.org/0000-0003-2025-4991)

Makine Mühendisliği Bölümü, Eskişehir Osmangazi Üniversitesi, Batı Meşelik Kampüsü Odunpazarı/Eskişehir 


\title{
Effect of Energy Input on Microstructural and Tribological Properties of WC Composite Coatings Produced by Plasma Transfer Arc (PTA) Method
}

\begin{abstract}
In this study, surface modification with tungsten carbide (WC) powder was applied on 1.2842 cold work tool steel using 3 different energy inputs by plasma transfer arc (PTA) method. Energy inputs were performed with different current values and feed rates during the process. Microstructure properties of the samples were determined by optical microscope, SEM, EDS and XRD analysis. Friction and wear properties were determined with pin-disk wear test method according to ASTM-G99 standard. Worn surfaces were examined by SEM and EDS analysis and wear mechanisms were determined. Hard carbide structures such as $\mathrm{WC}, \mathrm{Fe}_{3} \mathrm{~W}_{3} \mathrm{C}$ and $\mathrm{Fe}_{7} \mathrm{C}_{3}$ were formed in the interdendritic regions of the modified samples. The size of the interdendritic regions changed with the effect of energy inputs. Since the low energy input did not fully decompose the WC powder, it produced less $\mathrm{W}$ content carbide in the interdendritic regions. As a result of experimental studies, $0.9 \mathrm{~kJ} / \mathrm{mm}$ was determined as the optimum energy input. The hardness was increased approximately 5 times and the wear rate was reduced up to 7 times in WC coatings due to the formed hard carbide phases. The main wear mechanism of WC coatings was abrasive and oxidative wear.
\end{abstract}

Keywords- PTA surface modification, Heat input, Tungsten carbide, Friction and wear. 


\section{GİRIŞ}

Temas halinde çalışan haraketli makine parçalarında sürtünme ve aşınma önemli bir problemdir. Aşınma tespit edilemediğinde ciddi güvenlik tehditleri oluşturabilecek temel arıza türüdür. Çoğu malzeme ağır yükler ve yüksek sıcaklıklar gibi zorlu koşullarda düşük aşınma performansı gösterir [1]. Aşınmanın azaltılabilmesi için çeşitli yüzey ergitme ve alaşımlandırma işlemleri kullanılmaya devam etmektedir. Bunlardan en önemlileri lazerle yüzey ergitme (LSM) [2], gaz tungsten ark (TIG veya GTAW) [3] ve plazma transferli ark (PTA) [4] yöntemleridir. PTA yöntemi farklı özelliklerdeki kaplama tozlarının altlık malzemenin üzerinde ergitilmesi prensibine dayanır [5]. Yüksek enerji yoğunluğuna sahip plazma arkı altlık üzerine uygulandığında yüzeyi hızla eritir. $\mathrm{Bu}$ yöntemle, erimiş havuz içine kaplama tozları ilave edilerek metalürjik reaksiyonlar gerçekleştirilebilir. Alaşımlandırılmış havuz hızla katılaşarak, altlık malzeme ile metalürjik olarak bağlanmış, yüzey özellikleri değiştirilmiş tabakalar oluşturur. PTA yöntemi kullanılarak malzemelerin aşınma direnci ve korozyon dayanımı gibi yüzey özelikleri geliştirilebilir [6]. PTA tekniği yüksek birikme oranı, yüksek birikme verimliği, düşük 1sı girdisi, iyi metalürjik bağlanma ve düşük distorsiyon gibi önemli avantajları sayesinde yaygın olarak kullanılmaktadır [7]. PTA yüzey modifikasyon uygulamaları, petrol sondajı, maden sanayi, enerji üretimi, plastik ekstrüzyon, çelik yapımı ve petrokimya endüstrilerinde başarıyla uygulanmaktadır [4].

Kaplama tabakalarında daha yüksek aşınma dirençleri elde etmek için, sert seramik partikül ilavesi ile metal matrisli kompozit kaplamalar (MMK) üretilir [8]. Tungsten karbür (WC), yüksek sertlik, yüksek kimyasal stabilite, düşük termal genleşme, iyi aşınma ve oksidasyon direnci gibi üstün özellikleri sayesinde ilgi çekici özelliğe sahiptir. WC takviyeli kompozit kaplamaların üretilmesi için, WC tozu Co, Ni ve Fe gibi metal tozlarına karıştırılarak kullanılır [9]. WC partikülleri ve matris metal arasındaki ıslanabilirlik nedeniyle, kaplama sertliğini ve aşındırıcı aşınma direncini optimize etmek için farklı oranlarda WC partikülü metal hammadde tozu ile karıştırılır [10]. Son yıllarda, Co’ın yüksek fiyatını nedeniyle, Ni ve Fe tozlarının veya karışımlarının bağlayıcı özelliklerini iyileştirilmesi üzerine çalışmalar yapılmaktadır [11].

Literatürde, farklı altlık malzemeler ve alaşım tozları kullanılarak geliştirilen PTA kaplamalar yaygın olarak bulunmaktadır [12, 13]. Farklı altlık malzeme ve özellikle farklı alaşım tozlarının kullanılmasıyla mikroyapıdaki fazların değişimi, kaplamanın mekanik ve tribolojik özelliklerini önemli ölçüde değiştirmektedir. WC'ün sağlayabileceği üstün özelliklere rağmen, WC kaplama tabakalarının üretilmesi için oldukça az sayıda çalışma literatürde mevcuttur. Yuan and Li [14] çalışmalarında çelik üzerinde farklı oranlarda W, C, ve Fe alaşım tozları kullanarak PTA yöntemi ile MMK kaplamalar üretmiştir. Kaplama tabakasının $\mathrm{WC}, \mathrm{M}_{6} \mathrm{C}$ ve $\mathrm{\gamma}$ fazlarından oluştuğunu ve WC kristalinin yüksek sertlik ve iyi tokluğa sahip üçgen prizma yapısına dönüştüğü belirlemişlerdir. WC miktarını arttırarak WC / Fe karbür kaplamanın aşınma özelliğini doğrudan artırabileceğini vurgulamışlardır. Liyanage vd. [15] çalışmalında farklı oranlarda Ni içeriğine sahip alaşımlar ile WC takviyeli kaplama tabakalarını PTA yöntemi ile üretmişlerdir. Kaplama tabakasının y-Ni dendritleri, Ni tabanlı ötektik, borür ve karbür fazlardan oluştuğunu belirlemişlerdir. WC takviyesini kaplamanın sertliğini artırdığını ve aşınma direncini 2 ile 5 kat iyileştirdiğini tespit etmişlerdir. Kırılgan ikincil fazların ve matris tarafından daha az enerji emilimi nedeniyle, daha yumuşak matris alaşımının MMK kaplamalarda daha iyi performans sağladığını vurgulamışlardır. Yuan vd. [16] çalışmalarında FeNi matrisli WC ve WC/TiC takviyeli kaplamaları PTA yöntemi ile üretmiştir. Sertlik ve aşınma direncinin WC/TiC takviyeli kaplamalarda daha yüksek olduğunu belirlemişlerdir. Zhang vd. [17] çalışmalarında PTA yöntemi ile üretilen Ni tabanlı WC takviyeli MMK kaplamalara farklı oranlarda TiC ilavesinin mikroyapı, sertlik ve tribolojik özelliklere olan etkilerini incelemişlerdir. TiC ilavesiyle, WC / Ni bazlı kaplamadaki kaba dendritik yapının düzgün dağılmış bloklu mikroyapıya dönüştüğü tespit etmişlerdir. Kuru kayma aşınma testinde, \% 40 WC takviyeli Ni bazlı kaplama ile karşılaştırıldığında, TiC ilavesiyle hem sürtünme katsayısını hem de aşınma kaybının azaldığını vurgulamışlardır. Sundaramoorthy vd. [18] çalışmalarında 2 tip Ni taban (NiBSi ve NiCrBSi) ve 2 tip WC (makrokristalin WC ve döküm ötektik $\mathrm{WC} / \mathrm{W}_{2} \mathrm{C}$ ) tozu kullanarak PTA yöntemi ile MMK kaplamalar üretmişlerdir. Matris kimyası ve sertliğinin, aynı tip WC'ler kullanıldığında Ni/WC-MMK' lerin aşınma direnci üzerinde önemli bir etkisinin olmadığını vurgulamışlardır. Çelik [19] çalışmasında Ti6Al4V alaşımı üzerinde PTA yöntemi ile bağlayıcı kullanmadan WC-MMK kaplamalar üretmiştir. PTA işleminin sertlik ve aşınma direncini arttırdığı tespit etmiştir. PTA ark akımı kaplamanın sertliğini, mikroyapısını ve aşınma özelliklerini doğrudan etkilediğini vurgulamışlardır. Wei vd. [20] çalışmalarında Ni esaslı \%65 WC içeren Stelcar 65 tozunu çelik altlık üzerinde farklı akım değerleri, toz besleme hızı ve kaynak ilerleme hızları kullanarak PTA yöntemi ile kaplamışlardır. PTA işlem parametrelerinin WC' ün bozulması üzerinde önemli etkileri olduğunu 
vurgulamışlardır. Kaplama tabakasında WC bozulmasından sonra $\mathrm{Fe}_{3} \mathrm{~W}_{3} \mathrm{C}, \mathrm{FeW}_{3} \mathrm{C}$ ve $\mathrm{Ni}_{2} \mathrm{~W}_{4} \mathrm{C}$ fazlarının oluştuğunu tespit etmişlerdir. Optimum PTA işlem parametreleri olarak 100 A kaynak akımı, $25 \mathrm{~g} / \mathrm{dk}$ toz besleme hızı ve $40 \mathrm{~mm} / \mathrm{dk}$ kaynak ilerleme hızı olarak tespit etmişlerdir. Yüksek enerji girdisi kullanılarak yapılan PTA işlemlerinde (120 A), WC' ün bozulmasının şiddetlendiğini vurgulamışlardır.

PTA işlemi, düşük maliyetli, yüksek 1sı girdisi, yüksek verimlilik ve kolay kullanım özellikleri ile yüzey modifikasyon işlemleri için önemli bir enerji kaynağıdır. Bununla birlikte, PTA'nın WC üretmek için bir yöntem olarak kullanılması hakkında çok az araştırma bulunmaktadır. W zayıf bir karbür oluşturucu elementtir, erimiş havuzun siv1 fazda bekleme süresi, WC'ün metalürjik reaksiyon süresine ulaşmak için yetersiz olabilmektedir [14]. Bu nedenle yüksek sıcaklıktaki erimiş kaynak havuzunda bağlayıcı olarak kullanılan metallerin metalürjik reaksiyonu görülebilmektedir. Bu nedenle, bu çalışmada bağlayıcı matris kullanılmadan WC tozu çelik altlık üzerinde farklı enerji girdileri kullanılarak yüzey modifikasyon işlemleri yapılmıştır. Oluşan fazlar, sertlik ve aşınma özelliklerindeki değişimier incelenmiştir.

\section{MATERYAL VE YÖNTEMLER}

Altlık malzeme olarak 10x10x80mm boyutlarında 1.2842 soğuk iş takım çeliği kullanılmıştır. Bu altlık malzeme delme, sıvama, kesme ve enjeksiyon kalıplarında kullanılan, ısıl işlemler sonrası yağda sertleştirilebilen ve kimyasal bileşimi \% ağırlık olarak \%0.9 C, \%2 Mn, \%0.25 Si, \%0.4 Cr, \%0.1 V ve kalan\% Fe içeren çeliktir [21]. Altlık malzemenin yüzeyleri işlemler öncesi alkol ve aseton ile temizlenmiştir. Altık yüzeyine, ABCR Gute Chemie marka (AB202995), metal tabanlı, en az \%99.5 saflıkta, ortalama tane boyutu $1 \mu$ m olan WC tozu alkole karıştırılarak yerleştirilmiş̧tir. PTA yüzey eritme işlemi sırasında koruyucu gazın etkisiyle WC tozlarının yüzeyden uzaklaşmasını önlemek için, numuneler $250{ }^{\circ} \mathrm{C}$ 'de 1 saat fırında bekletilmiştir. Numunelerin üst yüzeyi Fronius PTW Plasma Module 10 plazma kaynak makinesiyle farklı enerji girdileri uygulanarak ergitilmiştir. Farklı enerji girdisi için farklı akım değerleri ve ilerleme hızları seçimi yapılmıştır. Seçilen parametrelerin, kaplama tozu içinde ikinci bir bağlayıcı madde olmadığı için yüksek sıcaklıkta eriyen WC tozunu eritmeye yetecek kadar yüksek olması sağlanmıştır. Enerji girdisi değerleri Denklem 1'e göre hesaplanmıştır.

$$
\mathrm{Q}=\mathrm{IxUx \eta} / \mathrm{V}
$$

Denklemde; Q: enerji girdisi (J/mm), I: ark akım değeri (A), U: ark gerilimi (V), V: PTA ilerleme hızı $(\mathrm{mm} / \mathrm{s})$ ve n: termal verimlilik katsayısı (PTA yöntemi için 0.6) değerleridir [22]. PTA Yüzey modifikasyon işlemlerine ait işlem parametreleri ve hesaplanan enerji girdisi değerleri Tablo 1'de verilmiştir. Yüzey eritme işlemi sırasında ticari saflık Argon gazı hem koruyucu gaz hem de plazma gazı olarak kullanılmıştır. Elektrot iş parçası arası mesafe $2.5 \mathrm{~mm}$ olarak seçilmiştir.

Tablo 1. PTA işlem parametreleri

\begin{tabular}{lccc}
\hline \multirow{2}{*}{\multicolumn{1}{c}{ PTA işlem parametreleri }} & \multicolumn{3}{c}{ Değerler } \\
\cline { 2 - 4 } & S1 & S2 & S3 \\
\hline Ark Akımı (A) & 90 & 100 & 100 \\
İlerleme Hızı (mm/dk) & 100 & 100 & 80 \\
Ark Gerilimi (V) & & $22-25$ \\
Tungsten Toryumlu Elektrot Çapı (mm) & 2.4 \\
Koruyucu Gaz Akış Oranı (1/dk) & & 12 \\
Plazma Gaz Akış Oranı (l/dk) & & 0.5 & \\
Elektrot İş Parçası Arası Mesafe (mm) & & 2.5 & \\
Enerji Girdisi (kJ/mm) & 0.713 & 0.9 & 1.125 \\
\hline
\end{tabular}

PTA yüzey alaşımlandırma işleminden sonra üretilen numunelerden mikroyapı, mikrosertlik ve aşınma numuneleri ıslak kesme yöntemi ile kesilmiştir. Numuneler 220 ve 600 grid manyetik zımpara diskleri ile zımparalanmış ve manyetik çuha ile $3 \mu \mathrm{m}$ elmas solüsyon çözeltisi kullanılarak parlatılmıştır. Mikroyapı 
numuneleri $1 \mathrm{~g} \mathrm{CuCl}_{2}+5 \mathrm{ml} \mathrm{HCl}+40 \mathrm{ml}$ alkol çözeltisi ile dağlanmıştır. Optik mikroyapılar için Nikon Clemex, taramalı elektron mikroskobu görüntüleri ve EDS analizleri için JEOL JSM-5600LV cihazları kullanılmıştır. X ışınları kırınımı (XRD) analizleri Bruker D8 cihazında, $\mathrm{Cu}-\mathrm{K} \alpha$ radyasyonu, $30^{\circ}-100^{\circ} 2$ teta açılarda ve $0,5^{\circ} / \mathrm{dk}$ tarama hızında yapılmıştır. Mikrosertlik ölçümleri Future Tech FM-700 cihazında 100 gf ve 10 sn bekleme sürelerinde gerçekleştirilmiştir. Sertlik dağılımları yüzeyden altlık malzemeye doğru $100 \mu \mathrm{m}$ aralıklarla ölçüm alınarak belirlenmiştir. Aşınma deneyleri CSM tribometrede pim-disk yöntemi kullanılarak, ASTM G99 standartlarında yapılmıştır. Aşınma deneyleri öncesinde numunelerin yüzeyleri $0.2 \mu \mathrm{m}$ değerine kadar parlatılmıştır. Aşınma deneyleri oda sıcaklığında, 3N yük, 100 metre kuru kayma mesafesinde, 190 dev/dk dönüş hızında ve $3 \mathrm{~mm}$ çaplı WC aşındırıcı karşı cisime karşı yapılmıştır. Aşınma testleri sırasında mesafeye bağlı sürtünme katsayısı değerleri kaydedilmiştir. Aşınma kanalları yüzey pürüzlülüğü ölçüm cihazı, SEM ve EDS analizleri ile incelenerek aşınma oranları hesaplanmış ve aşınma mekanizmaları araştırılmıştır.

\section{SONUÇLAR VE TARTIŞMA}

\section{A. Mikroyapı İncelemeleri}

PTA yöntemiyle farklı enerji girdileri kullanılarak üretilen kaplamaların optik mikroyapı görüntüleri Şekil 1'de verilmiştir. Kaplama tabakalarında mikroyapısal kusur tespit edilmemiştir. PTA kaynak işlemi sırasında, MMK kaplamlarda alaşım tozları çözülerek, yüksek sıcaklıktaki plazmanın termal etkisi altında yeniden kristalleştirilir. Seçilen PTA enerji girdisinin sağladığı yüksek sıcaklık ile WC tozları büyük oranda çözülmüş ve yeniden kristalleşerek yeni fazların oluşumu sağlanmıştır. Oluşan yapılar kaplama tabakası içinde homojen olarak dağılmıştır. MMK kaplama tabakası ile altlık malzeme arasında oldukça ince bir geçiş bölgesi oluşmuştur. Geçiş bölgesi MMK kaplamanın altlık malzemeye güçlü metalürjik bağlar ile bağlandığını göstermektedir. Geçiş bölgeleri genel olarak düzlemsel bir yapıdadır. MMK kaplama tabakalarında enerji girdisi ile ergiyip katılaşan bölgeler soğuma yönüne bağlı olarak dendritik katılaşma göstermiştir. Yüksek soğuma hızı sayesinde kaplama tabakalarında üçüncül dendrit kolları oluşmamıştır. Ancak enerji girdisinin değişimi ana dendrit kollarının hacimsel büyüklüğünü etkilemiştir. Yüksek enerji kullanılarak işlem gören S3 numunenin dendrit kollarının hacimsel olarak büyüdüğü Şekil 1c'de görülmektedir. Daha düşük enerji girdisi kullanılan S1 numunesinde ise dendritik yapının oluşumu diğer numeneler kadar belirgin değildir.
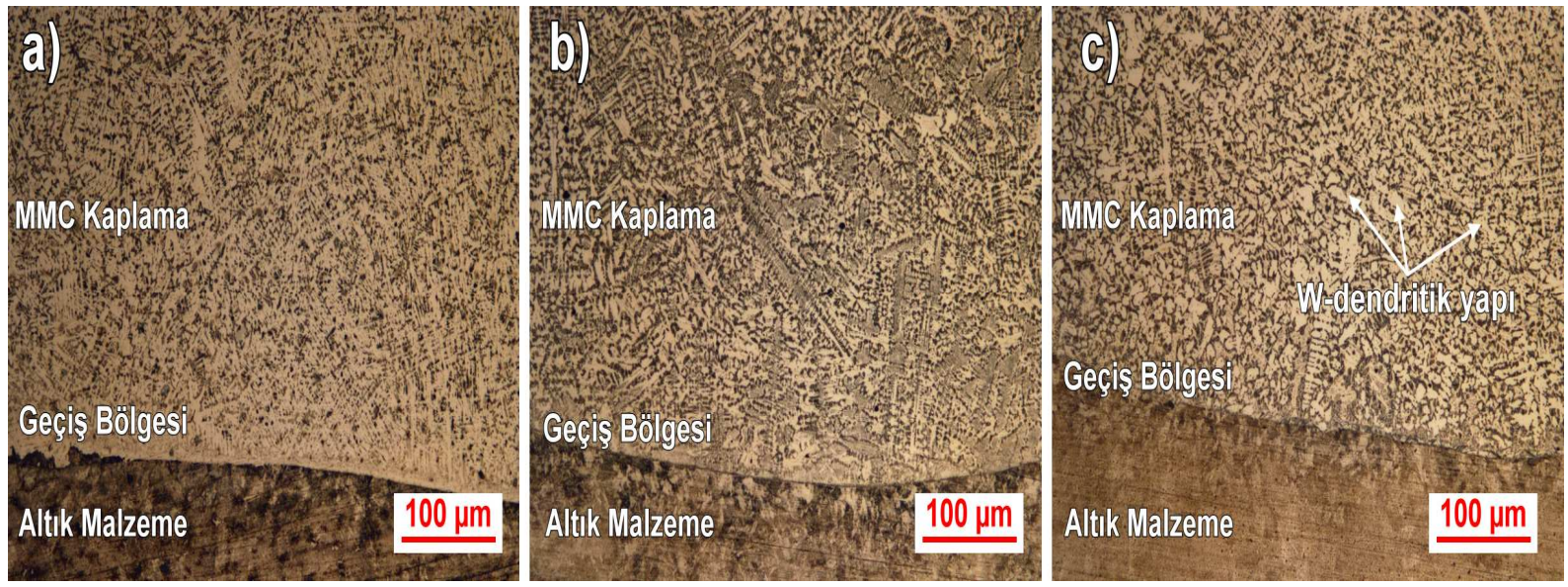

Şekil 1. WC-MMK kaplamaların genel mikroyapı görüntüsü: a) S1, b) S2, c) S3.

WC tozu ile elde edilen 3 adet MMK kaplama tabakasının mikroyapıları taramalı elektron mikroskobu (SEM) ve enerji dağılımlı X-ışını spektroskopisi (EDS) analizi ile incelenmiştir. Şekil 2'de verilmiş olan mikroyapıların SEM fotoğrafları ve Tablo 2'de verilen EDS analizleri incelendiğinde PTA işlemi sonrasında yüzeye büyük oranda $\mathrm{W}$ ve $\mathrm{C}$ elementi geçişi olduğu görülmektedir. Aynı zamanda altık çelikten yüksek miktarda Fe elementi geçişi olmuştur. Bileşiminde W bulunmayan çelik altlık malzemesindeki elementel artış kaplama işleminin başarılı olduğunu göstermektedir. WC'lerin etrafına altlık malzemeden difüze olan demir, FeW-C üçlü sisteminin oluşmasına neden olmuştur. PTA işlemi sırasında uygulanan enerji girdileri ile WC tozunun 


\begin{tabular}{|c|c|c|}
\hline & $\begin{array}{l}\text { BŞEÜ Fen Bilimleri Dergisi } \\
7(1), 251-264,2020\end{array}$ & $\begin{array}{r}\text { BSEU Journal of Science } \\
\text { DOI: } 10.35193 / \text { bseufbd.702519 }\end{array}$ \\
\hline U & & $8-7575$ (http://dergipark.gov.tr/bseufbd) \\
\hline
\end{tabular}

ayrışması sağlanmış ve eriyip katılaşan kaynak havuzunda yeni fazlar oluşmuştur. Bağlayıcı tozlar kullanılmadığı için çelik ve WC tozunun içeriğinin dışında herhangi bir element tespit edilmemiştir. Aynı zamanda kaynak havuzunu atmosferden korumak için seçilen argon gaz akış oranı yeterli olduğu için oksit ve benzeri yapılar tespit edilmemiştir. Enerji girdisi nedeniyle hızlı katılaşma sırasında oluşan dendrit kollarda yüksek W içeriği tespit edilmiştir. Bu dendrit kollarında soğuma hızının değişmesi nedeniyle farklı miktarlarda tungsten, karbon ve demir elementi içeriği tespit edilmiştir. Bu dendrit kollarında tungsten miktarı \%68.5 ile \%72.9 arasında değişmektedir. Dendritler arası bölgede farklı noktalardan yapılan analizlerde yapı içerisinde oldukça yüksek değerlerde demir ve tungsten içeriği tespit edilmiştir. Ayrıca bu bölgelerde karbon elementinin varlığı farklı birincil karbür yapılarının oluştuğunu göstermektedir (Şekil 2-a Nokta 2). Bu noktalardan yapılan EDS analizi Fe-W-C üçlü faz diyagramına [23] göre incelendiğinde yapının $\mathrm{M}_{3} \mathrm{C}(\mathrm{M}=\mathrm{Fe}$ ve $\mathrm{W})$ olduğu sonucuna varılmıştır. Ayrıca interdendritik bölgelerde ötektik iğnesel demir karbür yapıların varlığı tespit edilmiştir. Enerji girdilerinin değişimi ile alaşımlandırma bölgesinde farklı katılaşma hızlarının bir sonucu olarak farklı bileşimlerde karbürler oluşmuştur. Ayrıca enerji girdisinin artması WC tozunun ayrışmanı artırmıştır. Bu nedenle yüksek enerji girdisi kullanılan S3 numunesinde dendritik yapısında en yüksek W içeriği (Şekil 2-c nokta 1) tespit edilmiştir. Bu nedenle, bu numunenin dendritleri kısmen daha yoğun ve kaba kolonsal hale gelmiştir. Dendritik bölgede en düşük W içeriği (Şekil 2-b nokta 1) S2 numunesinde elde edilmiştir. Bu numunede $\mathrm{W}$ içeriği ilk katılaşan dendritik bölgede azalmasıyla, interdendritik bölgede daha fazla $\mathrm{M}_{3} \mathrm{C}$ fazları oluşturmuştur. S1 numunesinde ise enerji girdisi alaşım tozunu tam olarak ayrıştırmadığı için interdendritik bölgede oluşan $\mathrm{M}_{3} \mathrm{C}$ fazlarında diğer numunelere oranla azalma tespit edilmiştir.

Kaplama tabakalarının genel optik mikroyapı görüntülerinden ImageJ görüntü analiz programı kullanılarak dendritik ve interdendritik bölgelerin oranları tespit edilmiştir. Analiz sonuçları Tablo 3'te verilmiştir. MMK kaplamaların ana mikroyapısı kaplamanın üst yüzeyine doğru yönlenmiş dendritik ve interdendritik yapılardan oluşmaktadır. Dendritik kollar WC'ün bozulması sonucunda oluşan yüksek W içerirken, interdendritik bölgeler yüksek Fe içeriği ile ötektik sert karbürlerin oluştuğu bölgedir. S1 numunesinde ise enerji girdisi alaşım tozunu tam olarak ayrıştırmadığı için dendritik bölgede oluşan ana Fe-W dendritleri nedeniyle interdendritik bölge azalmıştır. S3 numunesinde artan 1sı girdisi ile numunenin daha yavaş soğuması dendrit kolların büyümesine neden olmuştur. Bu nedenle karbür içeren interdendritik bölgenin miktarı azalmıştır. S2 numunesinde en yüksek interdendritik bölge oranı belirlenmiştir. Bu numunenin de W içeriği ilk katılaşan dendritik bölgede azalmasıyla, interdendritik bölgede oranı artmıştır.
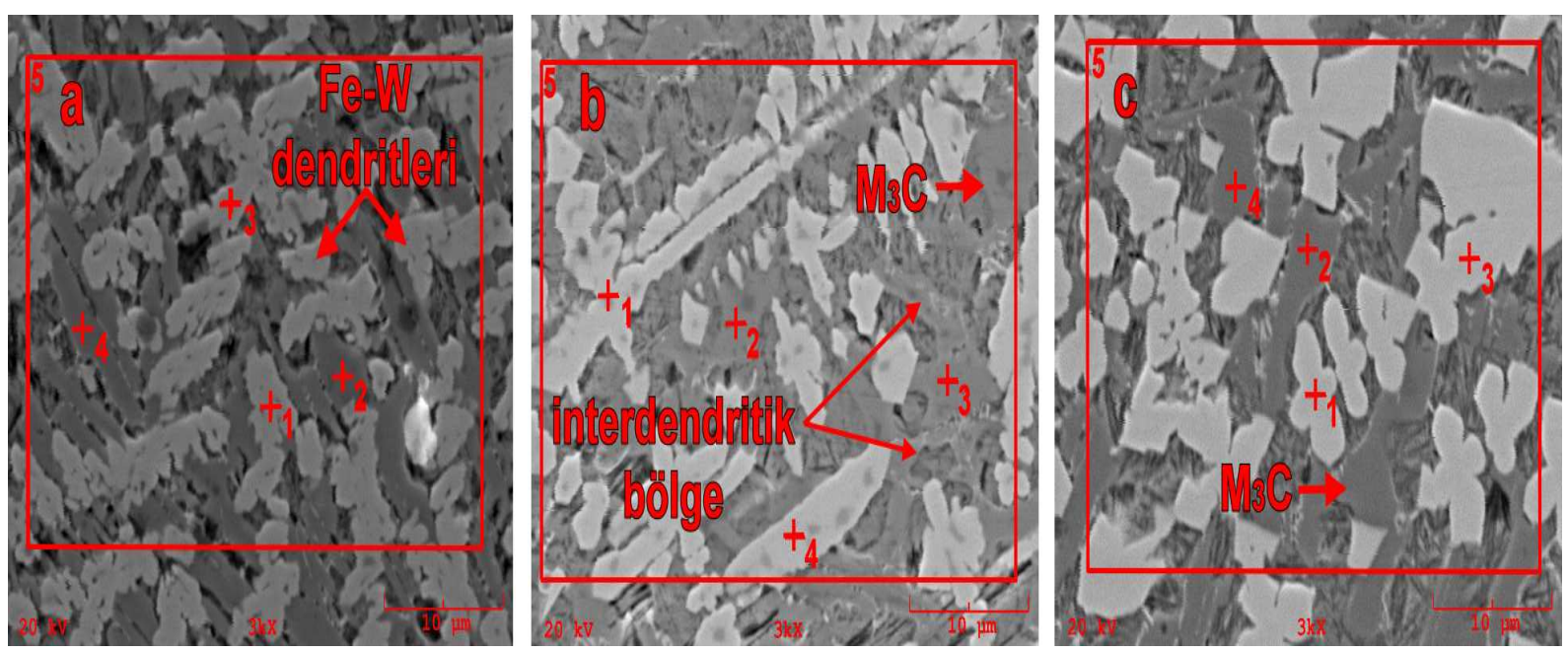

Şekil 2. WC-MMK kaplamaların SEM mikroyapı görüntüsü: a) S1, b) S2, c) S3. 
Tablo 2. MMK kaplamaların EDS analizi sonuçları

\begin{tabular}{ccccccccc}
\hline \multirow{2}{*}{ Numune } & Spek. & \multicolumn{7}{c}{ \% element } \\
\cline { 2 - 8 } & & Fe & W & C & Mn & Si & V & Cr \\
\hline \multirow{2}{*}{ S1 } & 1 & 24.347 & 71.276 & 1.103 & 2.47 & 0.439 & 0.113 & 0.252 \\
& 2 & 74.244 & 21.799 & 1.752 & 1.275 & 0.536 & 0.071 & 0.324 \\
& 3 & 26.131 & 70.233 & 0.378 & 2.456 & 0.466 & 0.104 & 0.232 \\
& 4 & 74.971 & 21.157 & 1.882 & 1.305 & 0.295 & 0.217 & 0.173 \\
& 5 & 58.131 & 38.215 & 1.096 & 2.214 & 0.095 & 0.092 & 0.158 \\
\hline \multirow{3}{*}{ S2 } & 1 & 27.263 & 68.482 & 0.683 & 2.59 & 0.572 & 0.165 & 0.245 \\
& 2 & 78.645 & 17.183 & 2.007 & 1.233 & 0.496 & 0.162 & 0.273 \\
& 3 & 77.593 & 17.436 & 2.697 & 1.254 & 0.62 & 0.053 & 0.346 \\
& 4 & 25.688 & 69.693 & 1.087 & 2.547 & 0.653 & 0.096 & 0.236 \\
& 5 & 52.982 & 43.401 & 1.203 & 1.375 & 0.779 & 0.028 & 0.232 \\
\hline \multirow{2}{*}{ S3 } & 1 & 22.858 & 72.9 & 0.846 & 2.77 & 0.374 & 0.0 & 0.253 \\
& 2 & 70.213 & 25.811 & 1.872 & 1.424 & 0.253 & 0.133 & 0.295 \\
& 3 & 25.370 & 70.908 & 0.707 & 2.227 & 0.505 & 0.089 & 0.194 \\
& 4 & 72.733 & 23.297 & 1.592 & 1.243 & 0.774 & 0.027 & 0.294 \\
& 5 & 51.287 & 44.283 & 1.46 & 1.686 & 0.793 & 0.175 & 0.315 \\
\hline
\end{tabular}

Tablo 3. MMK kaplamaların mikroyapı analiz sonuçları.

\begin{tabular}{lcc}
\hline \multirow{2}{*}{ Numuneler } & \multicolumn{2}{c}{ \% değer } \\
\cline { 2 - 3 } & dendritik & interdendritik \\
\hline S1 & 58.79 & 41.21 \\
S2 & 54.19 & 45.81 \\
S3 & 56.38 & 43.62 \\
\hline
\end{tabular}

WC-MMK kaplamaların XRD analizi Şekil 3'te verilmiştir. PTA işlemi sırasında kaynak havuzunda oluşan yüksek sıcaklık sayesinde WC kaplama tozunun büyük bir kısmı W ve C elementlerine ayrılmıştır. WC parçacıklarının erimiş havuzda çözülmesi, matristeki W ve C zenginleşmesine yol açmış ve bu nedenle katılaşan yapılarda yeni fazlar oluşmuştur. XRD analizi sonuçlarına belirlenen fazlar $\mathrm{W}_{0.02} \mathrm{Fe}_{0.98}$ (PDF 00-051-0939), $\mathrm{Fe}_{3} \mathrm{~W}_{3} \mathrm{C}$ (PDF 01-089-7205), WC (PDF 00-051-0939) ve $\mathrm{Fe}_{7} \mathrm{C}_{3}$ (PDF 00-017-0333) fazlarıdır. EDS ve XRD analizi birlikte incelendiğinde ana dendrit kollarının $\mathrm{W}_{0.02} \mathrm{Fe}_{0.98}$ bileşiği olduğu, karbür yapıların ise çoğunlukla interdendritik bölgede oluştuğu belirlenmiştir. $\mathrm{Fe}_{3} \mathrm{~W}_{3} \mathrm{C}$ fazına ait XRD pikleri incelendiğinde en şiddetli pik yoğunluğunun S2 numunesinde olduğu görülmektedir. Bu durum mikroyapi incelemeleri ile uygun olarak en yüksek sert karbür oranına sahip olduğunu doğrulamaktadır. Aynı zamanda bu numuneye ait $\mathrm{W}_{0.02} \mathrm{Fe}_{0.98}$ pikinin diğer numunelerden daha az olduğu tespit edilmiştir. Mikroyapı incelemeleri ile birlikte değerlendirildiğinde bu numuneye ait işlem şartlarının WC tozunun PTA ile kaplanmasında, alaşım tozunun daha büyük bir kısmının sert karbür oluşumunu sağladığı için optimum değerler olduğu sonucuna varılabilir. S3 numunesinde yüksek enerji girişi nedeniyle dendritlerin büyümesi $\mathrm{W}_{0.02} \mathrm{Fe}_{0.98}$ pik şiddetinin artması ile XRD analizinde doğrulanmıştır. $\mathrm{Bu}$ nedenle $\mathrm{W}$ içerikli sert karbürlerin oranında bir miktar azalma belirlenmiştir. S1 numunesinde ise enerji girdisi tam olarak WC tozunun ayrışmasını sağlayamadığı için interdendritik bölgede W içerikli sert karbür oluşumu için gerekli elementlerin miktarının diğer numunelerden daha az olmasına neden olmuştur. Bu numunede interdendritik bölgenin diğer numunelerden daha küçük olduğu sonucuyla uyumlu olarak, XRD analizinde $\mathrm{Fe}_{3} \mathrm{~W}_{3} \mathrm{C}$ pik şiddetinin azaldığı belirlenmiştir. 


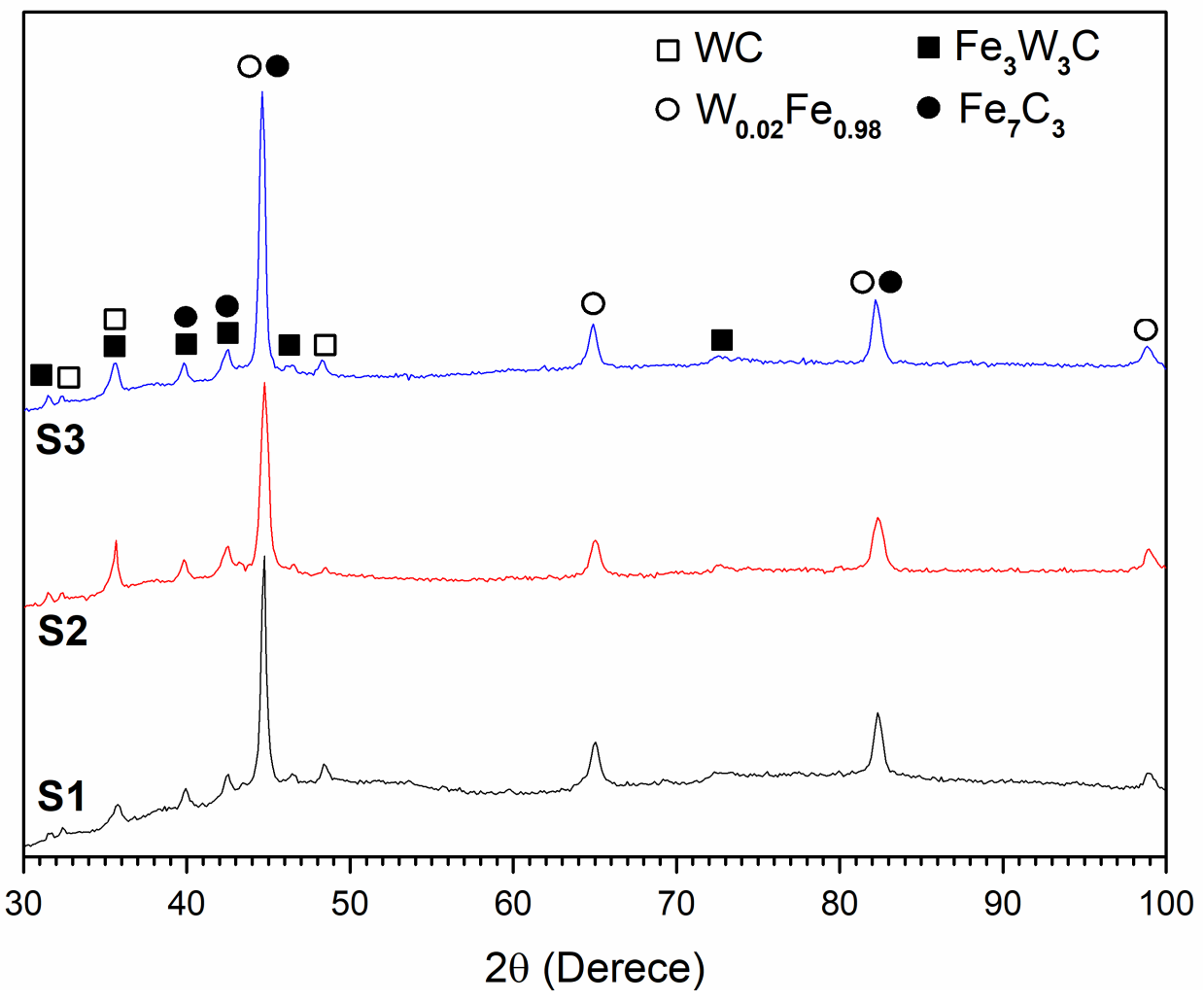

Şekil 3. WC-MMK kaplamaların XRD analizi sonuçları.

\section{B. Mikrosertlik Sonuçlart}

Yüzeyden altlık malzemeye doğru ölçülen mikrosertlik değerleri Şekil 4'te verilmiştir. Sertlik değeri, altlık çelik malzemenin sertliğinden oldukça yüksektir. Sert W içerikli karbürlerin yüksek konsantrasyonu, kaplama tabakalarındaki yüksek sertliğinin ana nedeni olmuştur. WC'lerin oluşturduğu yüksek sertlikteki interdendritik bölgedeki $\mathrm{M}_{3} \mathrm{C}(\mathrm{M}=\mathrm{Fe}, \mathrm{W})$ ve $\mathrm{Fe}_{7} \mathrm{C}_{3}$ karbürleri kaplama bölgesinin tüm tabakalarına dağıldı̆̆ için sertlik değerlerinde yüksek dalgalanmalar görülmemiştir. WC-MMK kaplamada sertlik değerleri yüzeyden altlık malzemeye doğru azalma eğilimindedir. S3 numunesinde yüksek enerjisi nedeniyle sert bölgelerin derinliği diğer numunelerden daha fazladır. S1 numunesinde ise düşük enerji girdisi nedeniyle sertleşmiş tabakaların derinliği diğer numunelerden daha azdır. PTA işlemi sırasında enerji girdisi alaşımlandırılan bölgenin derinliği arttırmıştır. Alaşımlandırılan bölgelerden sonra sertlik değerlerinde ciddi bir azalma tespit edilmiştir. Bu geçiş bölgelerinde enerji girdisi nedeniyle sertlik değerleri, altlık malzemenin sertliğinden biraz daha yüksektir. Sadece kaplama tabakalarındaki sertlik değerleri göz önüne alındığında S1 numunesinin ortalama sertliği 1066.3 $\mathrm{HV}_{0.1}$, S2 numunesinin ortalama sertliği $1178.3 \mathrm{HV}_{0.1}$ ve S3 numunesinin ortalama sertliği $1103.8 \mathrm{HV}_{0.1}$ olarak hesaplanmıştır. En yüksek sertlik değerine sahip S2 numunesinin değeri altlık malzemenin ortalama sertlik değerinin (235 HV) yaklaşık 5 katıdır. Numuneler arasında en yüksek sertlik değeri S2 numunesinde 1443.3 $\mathrm{HV}_{0.1}$ olarak ölçülmüştür. S2 numunesinde en yüksek interdendritik bölge oranı belirlenmiştir. Bu numunenin W içeriği ilk katılaşan dendritik bölgede azalmasıyla, interdendritik bölgede oranı artmıştır ve bu bölgede yoğun $\mathrm{M}_{3} \mathrm{C}(\mathrm{M}=\mathrm{Fe}, \mathrm{W})$ karbür yapısı oluşturmuştur. $\mathrm{M}_{3} \mathrm{C}(\mathrm{M}=\mathrm{Fe}, \mathrm{W})$ karbür yapısı en yüksek sertlik değerlerinin ana nedenidir [20]. Yüzeyden altlık malzemeye doğru sertlik değerlerinde az olsa da bir dalgalanma belirlenmiştir. Bunun nedeni demir matrisinin belirli yerlerinde oluşan farklı tipteki ve boyuttaki demir ve tungsten içerikli birincil karbürlerin varlığıdır. WC-MMK kaplama katmanlarında, sertlik değerleri birbirine oldukça yakın olarak ölçülmüştür. Bu durumun ana nedeni ise yapının aynı fazlardan oluşmasıdır. Ancak enerji girdisi nedeniyle fazların dağılımdaki değişiklikler sertlik değerlerinin değişmesine neden olmuştur. Kaplama kalınlığının arttırılması istendiğinde enerji girdisinin artırılması gerekirken, kaplama tabakasında daha yüksek sertlik değeri arzu edildiğinde S2 numunesine ait işlem şartlarının uygun değerler olduğu belirlenmiştir. 


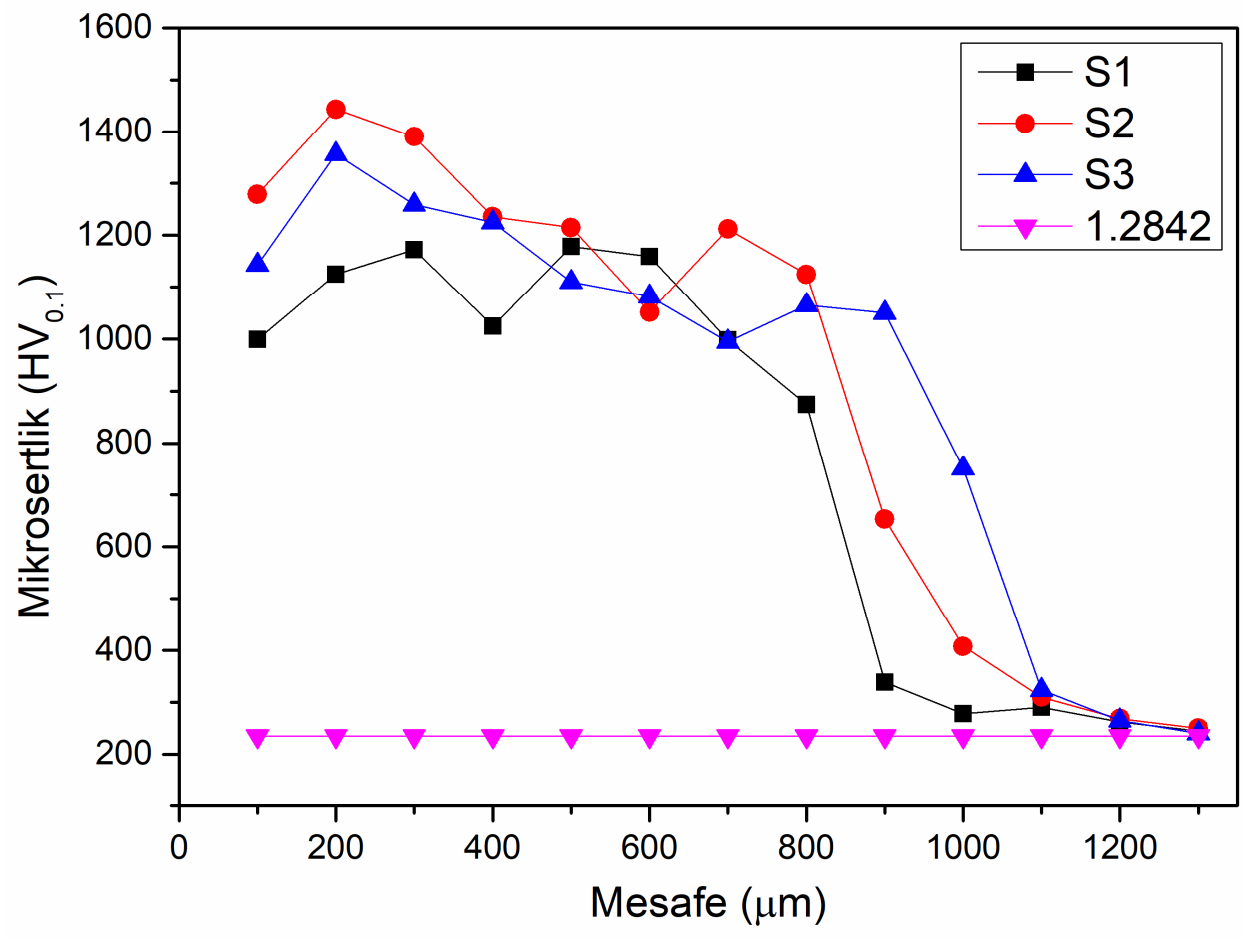

Şekil 4. WC-MMK kaplamaların mikrosertlik dağılımları.

\section{MMK Kaplamaların Sürtünme ve Aşınma Davranışları}

WC-MMK kaplamaların ortalama sürtünme katsayısı değerleri ve aşınma oranları Şekil 5'te verilmiştir. Kuru kayma test koşullarında, WC-MMK kaplamalar takım çeliğinden oldukça üstün aşınma davranışı göstermiştir. WC-MMK kaplamalar ile aşınma oranı 6.4 ile 7 kat azaltılmıştır. Bu sonuçlar, önemli derecede geliştirilmiş tribolojik davranışın mikroyapıda oluşan $\mathrm{WC}, \mathrm{M}_{3} \mathrm{C}(\mathrm{M}=\mathrm{Fe}, \mathrm{W})$ ve $\mathrm{Fe}_{7} \mathrm{C}_{3}$ sert karbürlerinin neden olduğuna işaret etmektedir. Kompozit kaplama numunelerinin ortalama sürtünme katsayısı değerleri, deney koşullarında 0.38 ile 0.41 arasında değişirken, altlık malzemenin ortalama sürtünme katsayısı 0.36 olarak ölçülmüştür. Farklı enerji girdileri ile PTA işlemi uygulanmış numunelerde farklı sürtünme katsayısı değerleri tespit edilmiştir.

Numunelerin kuru kayma mesafesine bağlı sürtünme katsayısı değişim grafiği Şekil 6'da verilmiştir. Aşınma kanallarının SEM görüntüleri Şekil 7'de ve EDS analizi sonuçları Tablo 4'te verilmiştir. Altlık çelik malzemenin sürtünme katsayısı değerleri yaklaşık 70 metre aşınma mesafesine kadar en düşük değerde iken bu mesafeden sonra artma eğilimine girmiştir. Bu numunenin aşınma kanallından alınan SEM ve EDS analizi sonuçlarına (Şekil 7-d) göre yüzeyde Fe ve W içerikli tribo-oksit tabakaları belirlenmiştir. Bu oksit tabakaları tribolojik sistemde sürtünme katsayını düşürmüş ve artan kayma mesafelerinde ve test yükünün etkisiyle kırılıp, yüzeyden ayrılarak geniş delaminasyon bölgeleri oluşturmuştur. Oluşan delaminasyon bölgeleri gerçek metalmetal temas alanını azalttığı için sürtünme katsayısını daha da düşürmüştür. Ancak 70 metrelik aşınma mesafesinden sonra kırılan oksit tabakları temas ara yüzeyinde kalarak sürtünmenin artmasına ve değerlerin dalgalanmasına neden olmuştur. S2 numunesinin sürtünme katsayısı mesafe diyagramı incelendiğinde yaklaşık 45 metreden sonra sürtünme katsayısının kararlı hale geçtiği belirlenmiştir. Bu numunenin aşınmış yüzey SEM ve EDS analizi (Şekil 7-b) incelendiğinde, oluşan Fe ve W içerikli oksit tabakaların aşınma yüzeyine tam olarak yayılmadığı ve kırılmadan yüzeye tutunduğu tespit edilmiştir. Oluşan oksit tabakaları temas yüzeyini tam olarak kaplamadığı için tribolojik sistemde metal-metal teması nedeniyle, bu numunede en yüksek sürtünme katsayısı değerleri elde edilmiştir. 


\begin{tabular}{|c|c|c|}
\hline & $\begin{array}{l}\text { BŞEÜ Fen Bilimleri Dergisi } \\
7(1), 251-264,2020\end{array}$ & $\begin{array}{r}\text { BSEU Journal of Science } \\
\text { DOI: } 10.35193 / \text { bseufbd.702519 }\end{array}$ \\
\hline VERSI & & 8-7575 (http://dergipark.gov.tr/bseufbd) \\
\hline
\end{tabular}

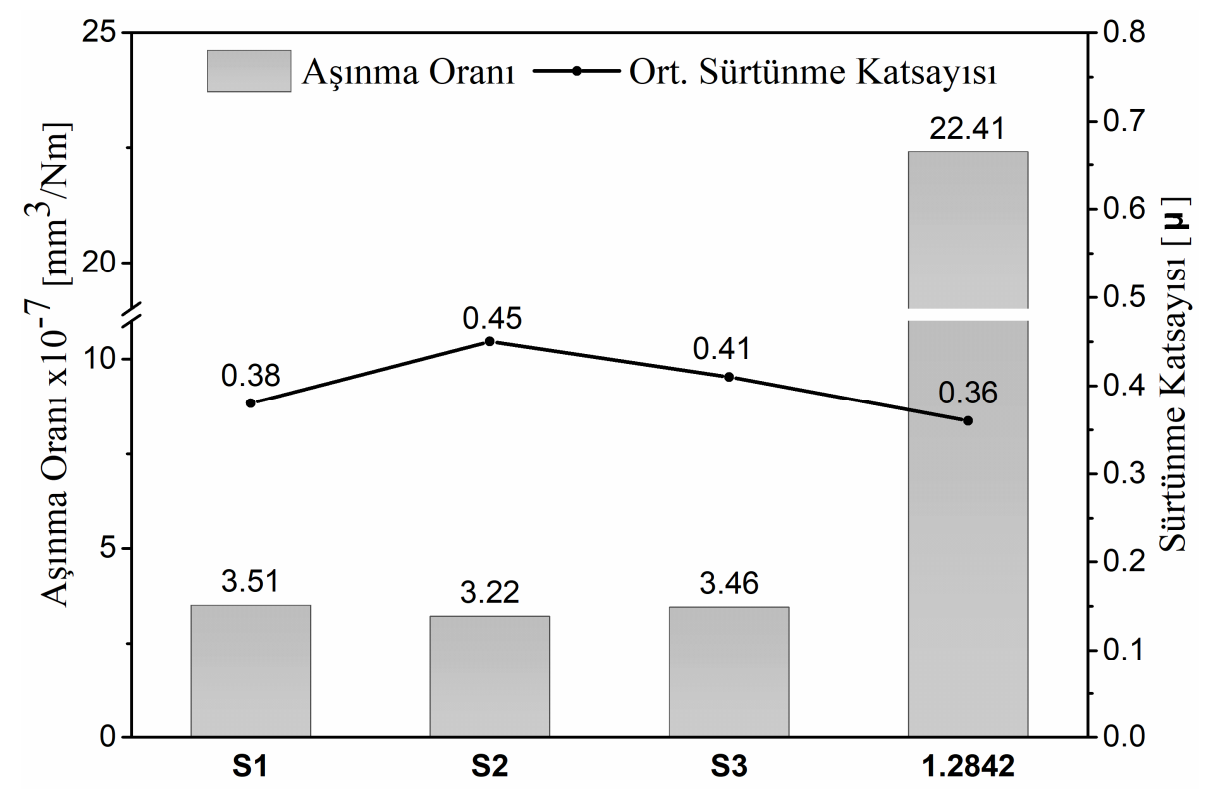

Şekil 5. Numunelerin aşınma oranları ve ortalama sürtünme katsayısı gösterimi değerleri.

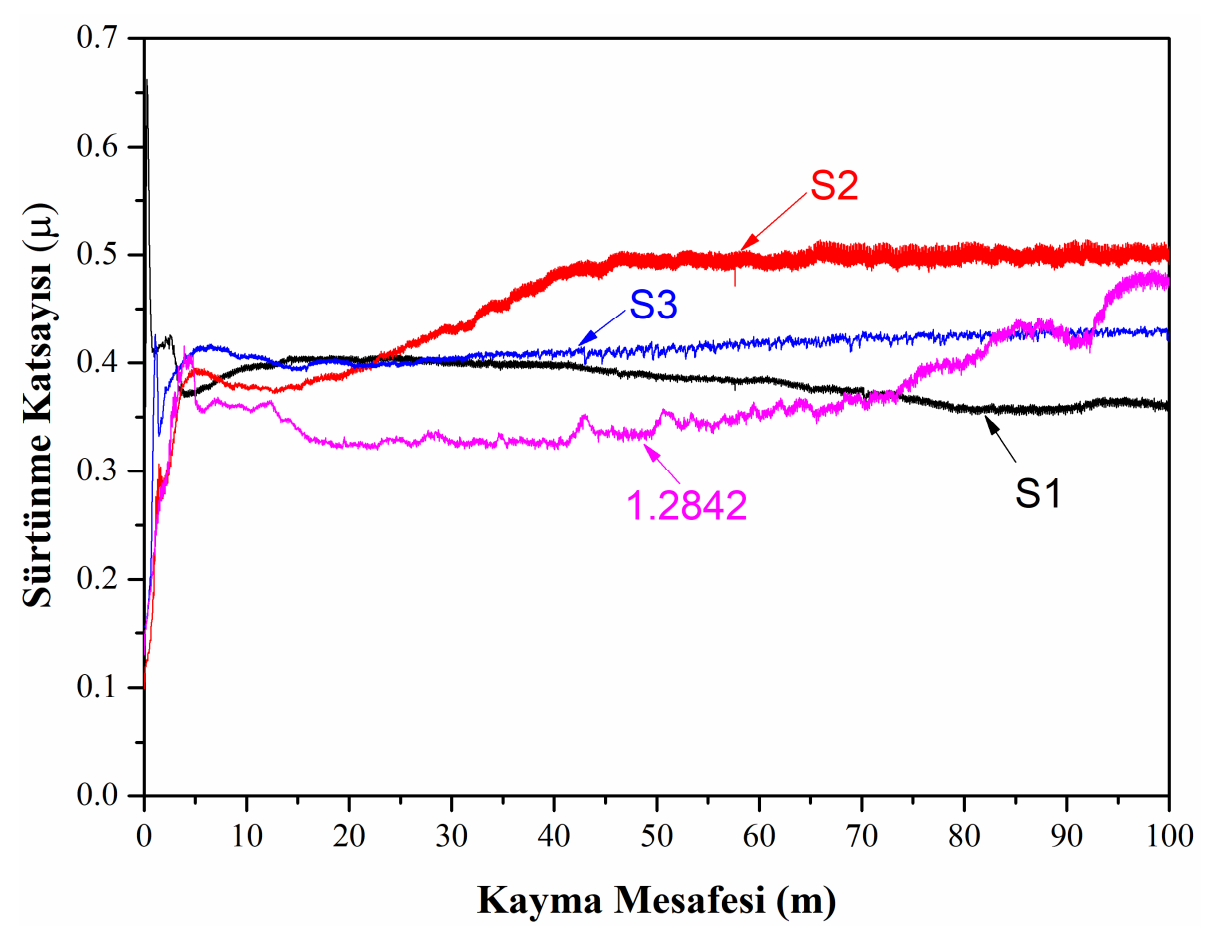

Şekil 6. Numunelerin kuru kayma mesafesine bağlı sürtünme katsayısı değişimi. 


\begin{tabular}{|c|c|c|}
\hline & $\begin{array}{l}\text { BŞEÜ Fen Bilimleri Dergisi } \\
7(1), 251-264,2020\end{array}$ & $\begin{array}{l}\text { BSEU Journal of Science } \\
\text { DOI: } 10.35193 / \text { bseufbd.702519 }\end{array}$ \\
\hline VERSI & & 58-7575 (http://dergipark.gov.tr/bseufbd) \\
\hline
\end{tabular}

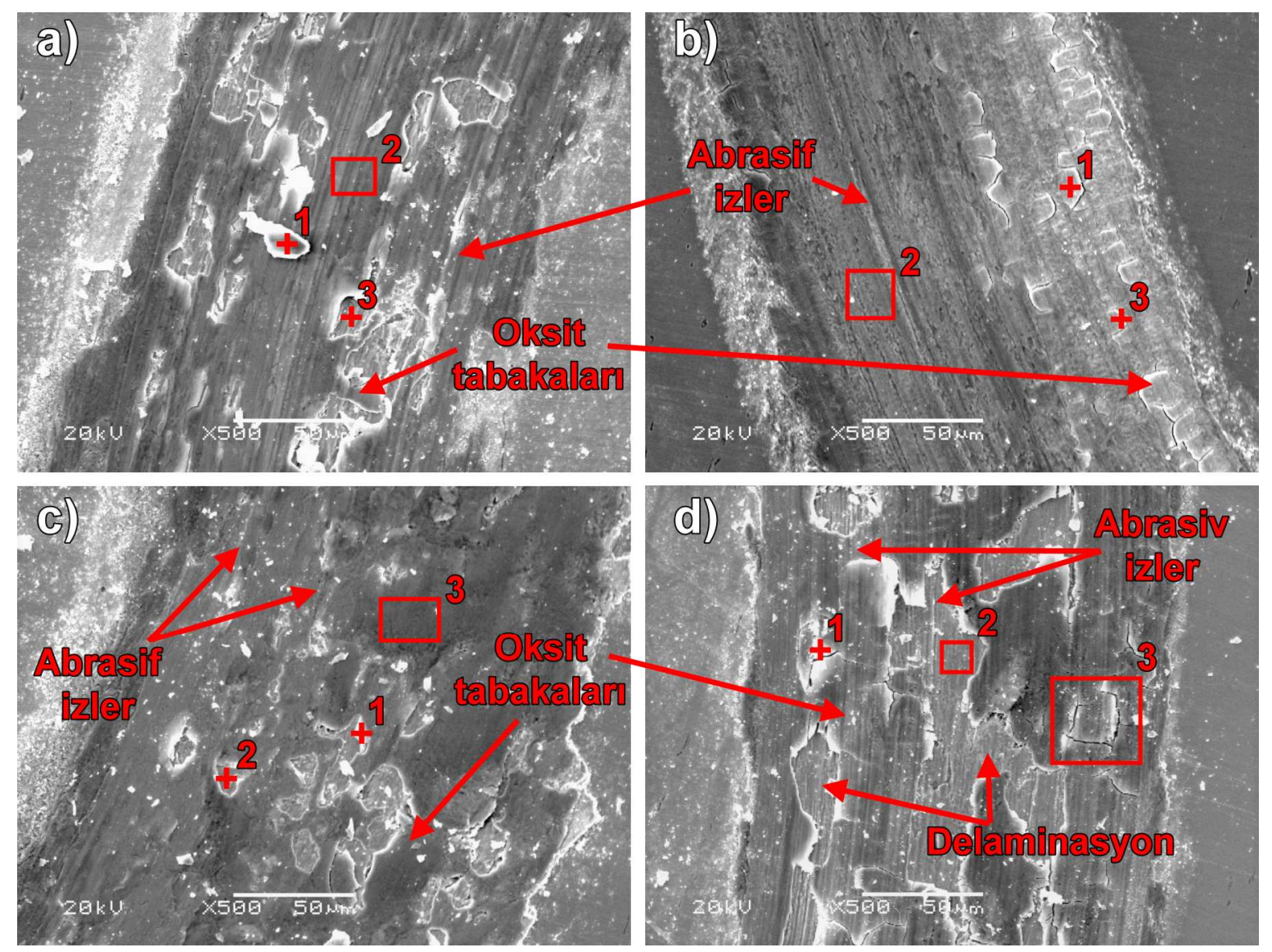

Şekil 7. Numunelerin aşınma kanallarının SEM görüntüsü: a) S1, b) S2, c) S3, d) Altlık malzeme.

Tablo 4. MMK kaplamaların EDS analizi sonuçları.

\begin{tabular}{cccccccccc}
\hline \multirow{2}{*}{ Numune } & \multirow{2}{*}{ Spek. } & \multicolumn{7}{c}{ \% element } \\
\cline { 3 - 10 } & & $\mathbf{F e}$ & $\mathbf{W}$ & $\mathbf{C}$ & $\mathbf{M n}$ & $\mathbf{S i}$ & $\mathbf{C r}$ & $\mathbf{V}$ & $\mathbf{O}$ \\
\hline \multirow{3}{*}{ S1 (a) } & 1 & 64.039 & 24.591 & 0.825 & 1.569 & 0.281 & 0.29 & 0.089 & 8.316 \\
& 2 & 71.129 & 14.853 & 0.572 & 1.706 & 0.314 & 0.249 & 0.184 & 10.993 \\
& 3 & 80.313 & 10.428 & 0.47 & 1.264 & 0.152 & 0.271 & 0.072 & 7.032 \\
\hline \multirow{3}{*}{ S2 (b) } & 1 & 45.191 & 43.697 & 0.433 & 1.95 & 0.085 & 0.209 & 0.187 & 8.249 \\
& 2 & 78.967 & 15.847 & 0.826 & 1.955 & 0.186 & 0.218 & 0.012 & 1.99 \\
& 3 & 62.363 & 27.048 & 0.729 & 1.457 & 0.212 & 0.304 & 0.081 & 7.771 \\
\hline \multirow{2}{*}{ S3 (c) } & 1 & 69.651 & 11.372 & 0.857 & 1.483 & 0.271 & 0.298 & 0.165 & 15.902 \\
& 2 & 79.716 & 9.171 & 1.16 & 1.443 & 0.165 & 0.175 & 0.178 & 7.992 \\
& 3 & 67.219 & 13.885 & 0.807 & 1.373 & 0.204 & 0.169 & 0.154 & 16.189 \\
\hline \multirow{2}{*}{$\mathbf{1 . 2 8 4 2}$} & 1 & 66.684 & 9.982 & 1.098 & 1.912 & 0.198 & 0.22 & 0.109 & 19.796 \\
$(\mathbf{d})$ & 2 & 92.665 & 2.282 & 0.958 & 1.987 & 0.315 & 0.383 & 0.193 & 1.217 \\
& 3 & 77.794 & 10.332 & 0.783 & 1.231 & 0.248 & 0.224 & 0.117 & 9.271 \\
\hline
\end{tabular}

S3 numunesinin sürtünme katsayısı mesafe diyagramından yaklaşık 10 metrelik kayma mesafesinden sonra kararlı hale geçiş görülmektedir. Bu numunenin aşınmış yüzey SEM ve EDS analizinde (Şekil 7-c) yüzeyde kalın oksit tabakalarının oluştuğu ve oldukça az miktarda delaminasyon bölgesi içerdiği tespit edilmiştir. Oluşan kalın oksit tabakaları artan kayma mesafesi ile kırılmadan yüzeyde kalmış ve kararlı hal sürtünme katsayısı elde edilmiştir. S1 numunesinin kayma mesafesi yaklaşık 35 metre üzerine çıtığında 
sürtünme katsayısı değerleri azalma eğilimine girmiştir. Bu numunenin aşınmış yüzey SEM ve EDS analizi incelendiğinde (Şekil 7-a) Fe ve W içerikli kalın oksit tabakalarının oluştuğu ve bu oksit tabakalarının kırılarak delaminasyona neden olduğu tespit edilmiştir. Oluşan oksit tabakaları altlık malzemeye göre daha kalın ve kompleks olduğu için, artan kayma mesafelerinde ve aşınma yükü etkisi ile daha az kırılmıştır. Bu nedenle tribolojik sisteme daha az kırılan oksit partikülleri dahil olmuştur. Bu numunede oluşan oksit tabakaları ve delaminasyon etkisiyle, sürtünme katsayısı 100 metre kayma mesafesine kadar azalma eğilimi göstermiştir.

Numunelerin aşınma kanallarında abrasif aşınma izleri ve tribo-oksit tabakaları Şekil 7'de açıkça gözükmektedir. WC-MMK kaplamaların aşınma kayıpları sert karşı cismin mikro-kazıma mekanizmasıyla yüzeyi aşındırması ve tribokimyasal reaksiyonlar sonrası oluşan oksitlerin test yükü ve artan kayma mesafelerinin etkisiyle yüzeyden ayrılması ile gerçekleşmiştir. WC-MMK kaplamaların mikroyapı incelemelerinde $\mathrm{WC}, \mathrm{M}_{3} \mathrm{C}(\mathrm{M}=\mathrm{Fe}, \mathrm{W})$ ve $\mathrm{Fe}_{7} \mathrm{C}_{3}$ karbürleri belirlenmiştir. Bu yüksek sertlikteki karbürlerin abrasif aşınma direnci ile aşınma miktarını büyük oranda azaltmıştır. Farklı enerji girdileri kullanılarak elde edilen kaplama tabakalarındaki karbür miktarı ve dağılımları abrasif aşınma dirençlerini etkileyerek, numunelerin tribolojik özelliklerini değiştirmiştir.

Çelik altlık malzemenin aşınmış yüzey SEM fotoğrafları (Şekil 7-d) incelendiğinde abrasif aşınma izleri ve oksit tabakaları görülmektedir. Bu numune kaplama tabaklarına göre daha düşük sertlikte olduğu için abrasif aşınma miktarı artmıştır. Aynı zamanda aşınma yüzeyinde oluşan tribo-oksit tabakaları artan kayma mesafeleri ve test yükünün etkisi ile kırılıp yüzeyden ayrıldığında, temas noktalarında kalıntı partiküller olarak davranmıştır. Bu partiküller, 3 cisimli abrazyona neden olduğu için aşınmayı daha şiddetlendirirmiştir. Bu nedenle altlık malzemenin genel aşınma mekanizması abrasif ve oksidatif aşınmadır. S1 numunesinin mikroyapı incelemelerinde belirlenen sert karbürler altlık çeliğe göre aşınma direncini büyük ölçüde artırmıştır. S3 numunesinde de benzer aşınma ve sürtünme davranışları elde edilmiştir. Ayrıca aşınmış yüzeyde Fe ve W içerikli oksit tabakalarının artan aşınma mesafelerinde tekrarlı yüklerle kırılması ve yüzeyden tabakalar halinde ayrılması sonucunda aşınma oranını bir miktar arttırmıştır. Bu nedenle S1 ve S3 numunesinde gerçek temas alanını kısmen azaltması nedeniyle sürtünme katsayısı değerleri S2 numunesine göre azalmış olsa da, yüzeyden ayrılan oksit tabaklarının 3 cisimli abrazyona neden olduğu için aşınma miktarı artırmıştır. S1 ve S3 numunelerinin mikrosertlik incelemeleriyle uyumlu olarak, S3 numunesin abrasif aşınma direnci bir miktar daha yüksektir. Bu nedenle S1 numunesi göre daha düşük aşınma oranı sergilemiştir. S1 ve S3 numunelerinin ana aşınma mekanizması abrasif ve oksidatif aşınma olarak tespit edilmiştir. En düşük aşınma oranı S2 numunesinde elde edilmiştir. Bu numunenin aşınma kanalları incelendiğinde (Şekil 7-b) diğer numunelere göre oldukça az tribo-oksit tabakaları belirlenmiştir. Oksit tabakaları aşınma kanalının belli bölgelerinde oluşmuş ve aşınma testi boyunca yüzeyden ayrılmadan kalmıştır. Bu nedenle bu numunenin sürtünme katsayısı diyagramında dalgalanma gözlenmemiştir. Oksit tabakaları yüzeyden ayrılmadığı için 3 cisimli abrazyon etkisi oldukça azdır. $\mathrm{Bu}$ numunenin ana aşınma mekanizması sert karşı cismin abrasif etkisine dayanmaktadır. Bu numunede mikroyapı incelemeleri sonucunda belirlenen $\mathrm{M}_{3} \mathrm{C}(\mathrm{M}=\mathrm{Fe}, \mathrm{W})$ gibi sert karbür yapısının yoğunluğu daha fazla olduğu için numunenin abrasif aşınma direnci artırmıştır. S2 numunesinde oksidatif aşınma etkisi oldukça azdır. $\mathrm{Bu}$ nedenle ana aşınma mekanizması abrasif aşınmadır. Seçilen enerji girdilerine göre S2 numunesin işlem şartları, aşınma direnci için uygun değer olarak belirlenmiştir.

\section{SONUÇLAR}

WC tozu kullanılarak takım çeliğinin üzerinde farklı enerji girdilerinde PTA yöntemi ile MMK kaplamalar başarı ile üretilmiştir. Elde edilen sonuçlar maddeler halinde aşağıda özetlenmiştir:

- Bağlayıcı kullanılmadan WC tozunun PTA yöntemi ile kullanılmasında belirli yükseklikte enerji girdisine ihtiyaç duyulmaktadır. Enerji girdisinin değişimi ana dendrit kollarının hacimsel büyüklüğünü etkilemiştir.

- WC-MMK kaplama tabakalarının mikroyapı incelemeleri ile ana dendrit kollarının yüksek demir ve tungsten içerikli olduğu ve karbür yapıların ise çoğunlukla interdendritik bölgede oluştuğu belirlenmiştir. XRD analizi sonuçlarına göre, $\mathrm{W}_{0.02} \mathrm{Fe}_{0.98}$ (PDF 00-051-0939), $\mathrm{Fe}_{3} \mathrm{~W}_{3} \mathrm{C}$ (PDF 01-0897205), WC (PDF 00-051-0939) ve $\mathrm{Fe}_{7} \mathrm{C}_{3}$ (PDF 00-017-0333) fazları oluşmuştur. 
- S2 numunesinde $\mathrm{W}$ içeriği ilk katılaşan dendritik bölgede azalıp, interdendritik bölgede artarak yoğun $\mathrm{M}_{3} \mathrm{C}(\mathrm{M}=\mathrm{Fe}, \mathrm{W})$ karbür yapısı oluşturmuştur. S1 numunesinde ise enerji girdisi alaşım tozunu tam olarak ayrıştırmadığı için dendritik bölgede oluşan ana $\mathrm{Fe}-\mathrm{W}$ dendritlerin nedeniyle interdendritik bölge azalmıştır. S3 numunesinde artan 1Sı girdisi ile numunenin daha yavaş soğuması dendrit kolların büyüterek interdendritik bölgenin bir miktar azalmasına neden olmuştur.

- İnterdendritik bölgede oluşan sert karbürler, mikrosertlik değerlerinde önemli artışa neden olmuştur. WC-MMK kaplamalar ile altlık malzemenin sertliği 5 kata kadar artırılabilmiştir. En yüksek ortalama sertlik değeri $1178.3 \mathrm{HV}_{0.1}$ olarak S2 numunesinde belirlenmiştir. PTA enerji girdisi artırıldığında sertleşen bölgenin derinliği artmıştır.

- WC-MMK kaplamaların mikroyapısında oluşan WC, $\mathrm{M}_{3} \mathrm{C}(\mathrm{M}=\mathrm{Fe}, \mathrm{W})$ ve $\mathrm{Fe}_{7} \mathrm{C}_{3}$ sert karbürler sayesinde, aşınma direnci 6.4 ile 7 kat artırılmıştır. WC-MMK kaplamaların ana aşınma mekanizması abrasif ve oksidatif aşınma olmuştur. S2 numunenin yüksek karbür oranının sağladığı sertlik aşınma oranını azaltmıştır.

- WC-MMK kaplamalarda seçilen 3 farklı enerji girdisi değerleri; mikroyapı, sertlik, sürtünme ve aşınma özelliklerini oldukça etkilemiştir. WC-MMK kaplama tabakalarında yüksek aşınma direnci arzu edildiğinde 3 farklı enerji girdisi içinden, $0.9 \mathrm{~kJ} / \mathrm{mm}$ enerji girdisi değeri deneysel çalışmalar sonucunda optimum olarak belirlenmiştir.

\section{KAYNAKLAR}

[1] Wang, J., Zhang, B., Yu, Y., Zhang, Z., Zhu, S., Lou, X., \& Wang, Z. (2020). Study of high temperature friction and wear performance of $(\mathrm{CoCrFeMnNi}) 85 \mathrm{Ti15}$ high-entropy alloy coating prepared by plasma cladding. Surface and Coatings Technology, 384.

[2] Yi, P., Liu, Y., Shi, Y., Jang, H., \& Lun, G. (2011). Investigation on the process of laser surface melting using two sequential scans. The International Journal of Advanced Manufacturing Technology, 57, (1-4), 225-233.

[3] Maleque, M. A., Ghazal, B. A., Ali, M. Y., Hayyan, M., \& Ahmed, A. S. (2015). Wear Behaviour of TiC Coated AISI 4340 Steel Produced by TIG Surface Melting. Materials Science Forum, 819, 76-80.

[4] Acevedo-Dávila, J. L., Muñoz-Arroyo, R., Hdz-García, H. M., Martinez-Enriquez, A. I., Alvarez-Vera, M., \& Hernández-García, F. A. (2017). Cobalt-based PTA coatings, effects of addition of TiC nanoparticles. Vacuum, 143, 14-22.

[5] Gür, A. K., Cengiz, M. H., Yıldız, T., \& Taşkaya, S. (2018). Plazma Transferli Ark Kaynak Yöntemiyle Hardox 400 Çelik Malzemenin Yüzeyinin Farklı Oranlardaki FeCrC Tozuyla Alaşımlandırılması. Fırat Üniversitesi Mühendislik Bilimleri Dergisi, 30, (1), 233-242.

[6] Dai, W., Miao, Y., Li, J., Zheng, Z., Zeng, D., \& Huang, Q. (2016). Investigation on morphology and micro-hardness characteristic of composite coatings reinforced by PTA copper alloying on nodular cast iron. Journal of Alloys and Compounds, 689, 680-692.

[7] Buytoz, S., Orhan, A., Gur, A. K., \& Caligulu, U. (2013). Microstructural Development of Fe-Cr-C and B4C Powder Alloy Coating on Stainless Steel by Plasma-Transferred Arc Weld Surfacing. Arabian Journal for Science and Engineering, 38, (8), 2197-2204.

[8] Liu, T., Chang, M., Cheng, X., Zeng, X., Shao, H., \& Liu, F. (2020). Characteristics of WC reinforced Nibased alloy coatings prepared by PTA + PMI method. Surface and Coatings Technology, 383,

[9] Yang, J., Liu, F., Miao, X., \& Yang, F. (2012). Influence of laser cladding process on the magnetic properties of WC-FeNiCr metal-matrix composite coatings. Journal of Materials Processing Technology, 212, (9), 1862-1868. 
[10] Yao, S. H. (2014). Tribological behaviour of NiCrBSi-WC(Co) coatings. Materials Research Innovations, 18, (sup2), S2-332-S2-337.

[11] Chang, S.-H. \& Chang, P.-Y. (2014). Investigation into the sintered behavior and properties of nanostructured WC-Co-Ni-Fe hard metal alloys. Materials Science and Engineering: A, 606, 150-156.

[12] Kılıçay, K. (2017). Mikroalaşımlı 38MnVS6 çeliğine uygulanan farklı yüzey ve ısıl işlemlerin mekanik özelliklere etkilerinin araştırılmast. Doktora Tezi, Eskişehir Osmangazi Üniversitesi, Fen Bilimleri Enstitüsü, Eskişehir.

[13] Ulutan, M., Kiliçay, K., Çelik, O. N., \& Er, Ü. (2016). Microstructure and wear behaviour of plasma transferred arc (PTA)-deposited FeCrC composite coatings on AISI 5115 steel. Journal of Materials Processing Technology, 236, 26-34.

[14] Yuan, Y. \& Li, Z. (2017). Microstructure and tribology behaviors of in-situ WC/Fe carbide coating fabricated by plasma transferred arc metallurgic reaction. Applied Surface Science, 423, 13-24.

[15] Liyanage, T., Fisher, G., \& Gerlich, A. P. (2012). Microstructures and abrasive wear performance of PTAW deposited Ni-WC overlays using different Ni-alloy chemistries. Wear, 274-275, 345-354.

[16] Yuan, Y., Wu, H., You, M., Li, Z., \& Zhang, Y. (2019). Improving wear resistance and friction stability of FeNi matrix coating by in-situ multi-carbide WC-TiC via PTA metallurgical reaction. Surface and Coatings Technology, 378,

[17] Zhang, M., Li, M., Chi, J., Wang, S., Ren, L., Fang, M., \& Zhou, C. (2019). Microstructure evolution, recrystallization and tribological behavior of TiC/WC composite ceramics coating. Vacuum, 166, 64-71.

[18] Sundaramoorthy, R., Tong, S. X., Parekh, D., \& Subramanian, C. (2017). Effect of matrix chemistry and WC types on the performance of Ni-WC based MMC overlays deposited by plasma transferred arc (PTA) welding. Wear, 376-377, 1720-1727.

[19] Çelik, O. N. (2013). Microstructure and wear properties of WC particle reinforced composite coating on Ti6Al4V alloy produced by the plasma transferred arc method. Applied Surface Science, 274, 334-340.

[20] Wei, Y., Wei, X.-s., Chen, B., Zuo, J.-y., Ma, T.-c., \& Shen, J. (2018). Parameter optimization for tungsten carbide/Ni-based composite coating deposited by plasma transferred arc hardfacing. Transactions of Nonferrous Metals Society of China, 28, (12), 2511-2519.

[21] Erkendirci, Ö. F. (2012). Effect of the Inclined Edge Notches on the Fatigue-Fracture Behavior of Soft Annealed and Quenched AISI O2 Tool Steel. Transactions of the Indian Institute of Metals, 65, (4), 399404.

[22] Gür, A. K. (2013). Investigating the Wear Behaviour of FeCrC/B4C Powder Alloys Coating Produced by Plasma Transferred Arc Weld Surfacing Using the Taguchi Method. Materials Testing, 55, (6), 462-467.

[23] Hiroaki, O., Mark E., S., \& Erik M., M. (1992). ASM Handbook Volume 3: Alloy Phase Diagrams. ASM International, 512. 